exposées dans notre première étude (Le Lait, janvier 1936, p. 20), renforce notre conviction qu'il y a lieu de condamner absolument la désacidification électrique du lait.

\title{
L'INFLUENCE DE L'AGE DU LAIT SUR LA SENSIBILITÉ DE LA RÉACTION DE STORCH
}

\author{
par
}

\section{Dr Jaroslay MASEK}

De l'Institut lactologique de l'Ecole Polytechnique à Prague.

(Directeur : Professeur Dr O. LAxA, Tchécoslovaquie.)

MM. Orla-Jensen et Winther (1) ont mentionné dans ce journal des observations très intéressantes sur la réaction de Storch servant à distinguer le lait cru du lait pasteurisé. Déjà Tномé et JORGENSEN ont pu observer, que le lait pasteurisé, ayant montré tout de suite après le chauffage une réaction négative, a donné par la suite une réaction positive. ORLA-JENSEN et Winther eux-mêmes citent le fait : le lait chauffé à $88^{\circ} \mathrm{C}$. restant sans couleur par les réactifs de Storch et prenant ensuite une coloration nette, observée 21 heures après le chauffage.

Je peux confirmer ces observations dans le lait pasteurisé et mélangé avec le lait cru. J'ai partagé le lait en deux parties : l'une d'elles a été pasteurisée pendant une minute à $85^{\circ} \mathrm{C}$., et à la moitié du lait ainsi chauffé, j'ai ajouté du lait cru. Pour l'expérimentation, ont donc été préparés deux échantillons de lait : l'un contenait du, lait pasteurisé, l'autre un mélange de lait pasteurisé et de lait cru dans une proportion de 10/3. Les deux échantillons ont été soumis à la réaction de Storch immédiatement après la préparation des échantillons et ensuite après les avoir laissé 24 heures à une température de $17^{\circ} \mathrm{C}$.

Le lait pasteurisé, ne se colorant à l'origine d'aucune façon, a pris une couleur teintée grisâtre quand il a été soumis à la réaction après 24 heures, c'est-à-dire que, quoique fournissant une réaction négative, il a pourtant montré plus tard une petite tendance vers la réaction positive. Le mélange de lait pasteurisé et de lait cru a donné une réaction positive, mais, dans les 24 heures, elle a montré une coloration gris bleuâtre, done, en fait négative. Les conditions y sont visiblement renversées.

Il se peut done que l'influence de la fermentation lactique se manifeste et, qu'en somme l'augmentation de l'acide lactique influe sur la sensibilité de la réaction de Storch ; c'est pourquoi j'ai fait les observations suivantes. J'ai ajouté au lait pasteurisé et au lait mélangé une dose d'acide lactique normale suffisante pour que 
l'acidité du lait s'élevât à environ $35^{\circ} \mathrm{D}$. Or, on a pu observer que le lait mélangé a pris une couleur gris bleuâtre, de même que le lait laissé au repos 24 heures, tandis que le lait pasteurisé ne s'est guère coloré. La coloration teintée grisâtre du lait pasteurisé laissé au repos pendant 24 heures à une température de $17^{\circ} \mathrm{C}$. ne peut donc être expliquée par l'augmentation de l'acide lactique. D'ailleurs, dans ce lait, la fermentation lactique n'a pu se manifester, mais bien en réalité dans le lait mélangé.

Outre la réaction de Storch, j'ai soumis, de plus, les deux

TABLEAU

\begin{tabular}{|c|c|c|c|}
\hline Réaction & Sorte de lait & Lait pasteurisé & Mélange \\
\hline \multirow{3}{*}{ Réaction de Storch } & Immédiatement & blane & bleu foncé \\
\hline & $\begin{array}{l}24 \text { heures après } \\
\text { la pasteurisa- } \\
\text { tion }\end{array}$ & teinté grisâtre & grise bleuâtre \\
\hline & $35^{\circ} \mathrm{D}$ & blane & grise bleuâtre \\
\hline \multirow{3}{*}{$\begin{array}{l}\text { Réaction de Schern- } \\
\text { Schellhase...... }\end{array}$} & Immédiatement & blanc & bleu foncé \\
\hline & $\begin{array}{l}24 \text { heures après } \\
\text { la pasteurisa- } \\
\text { tion }\end{array}$ & blane & bleu foncé \\
\hline & $35^{\circ} \mathrm{D}$. & blane & bleu foncé \\
\hline
\end{tabular}

échantillons de lait à la réaction de Schern-Schellhase (2), qui est tout particulièrement sensible aux traces de la peroxydase. J'ai pu observer que le lait mélangé a toujours présenté une réaction positive, que le lait ait été soumis à la réaction, immédiatement, ou bien, après un repos de 24 heures à une température de $17^{\circ} \mathrm{C}$., ou bien, qu'il ait été acidifié à $35^{\circ} \mathrm{D}$. Le lait pasteurisé sans addition de lait cru, ne s'est guère coloré, qu'il se soit agi de lait frais, de lait ancien ou de lait acidifié.

D'après ces observations, on peut conclure, que la réaction de Storch est sensible aux modifications subies par le lait pasteurisé haut et laissé au repos, tandis que la réaction de Schern-Schellhase ne possède pas cette sensibilité.

BIBLIOGRAPHIE

[1] Le Lait, 1935 , p. 247.

[2] Berl. Tierärztl. Wochenschr., 1911, p. 868. 